\title{
Body composition and nutritional and metabolic parameters in postmenopausal women sufficient, insufficient and deficient in vitamin D
}

Luisa Amábile Wolpe Simas', Leila Caroline Bianchet Zanatta', Carolina Aguiar Moreira', Victoria Zeghbi Cochenski Borba', Cesar Luiz Boguszewski'

\begin{abstract}
Objective: We investigated changes in body composition and nutritional and metabolic parameters in a group of postmenopausal women who were classified as sufficient, insufficient and deficient in vitamin D. Subjects and methods: A total of 106 postmenopausal women were included in this cross-sectional study and classified according to their serum levels of $25-\mathrm{OH}$-vitamin $\mathrm{D}$ as sufficient ( $\geq 30 \mathrm{ng} / \mathrm{mL}$; group S), insufficient (20.1 and $29.9 \mathrm{ng} / \mathrm{mL}$; group I) or deficient ( $\leq 20 \mathrm{ng} / \mathrm{mL}$; group D) in vitamin D. Body composition was measured by dual-energy X-ray absorptiometry (DXA); dietary recall questionnaires were completed; and blood samples were analysed to compare the metabolic and nutritional status of the study groups. Results: Eleven $(10.4 \%)$ of the women were classified in group S, $50(47.2 \%)$ in group I and $45(42.4 \%)$ in group D, with a mean serum level for $25-\mathrm{OH}-\mathrm{D}$ of $21.1 \pm 7.0 \mathrm{ng} / \mathrm{mL}$ in all participants. Body composition did not differ among the groups. Serum levels of 25-OH-D were negatively correlated with serum levels of triglycerides, total cholesterol and LDL cholesterol. Conclusions: Vitamin D insufficiency and deficiency were highly prevalent in our group of postmenopausal women, showing an association with an unfavourable lipid profile. Arch Endocrinol Metab. 2019;63(3):265-71
\end{abstract}

Keywords

Vitamin D; body composition; nutrition; metabolic syndrome; menopause
${ }^{1}$ Serviço de Endocrinologia e Metabologia (SEMPR), Departamento de Medicina Interna, Universidade Federal do Paraná, Curitiba, PR, Brasil

Correspondence to:

Cesar Luiz Boguszewski

Servico de Endocrinologia e

Metabologia,

Hospital de Clínicas,

Universidade Federal do Paraná

Avenida Agostinho Leão Junior, 285

80030-110 - Curitiba, PR, Brasil

clbogus@uol.com.br

Received on Aug/15/2018 Accepted on Feb/9/2019

DOI: 10.20945/2359-3997000000121

\section{INTRODUCTION}

$\mathrm{V}$ itamin D deficiency is a worldwide public health problem (1), even in regions and areas with sun exposure for most of the year. In Brazil, several studies have confirmed a high prevalence of hypovitaminosis D $(2,3)$. Serum vitamin D levels may be affected by a number of factors (4), and there is a higher prevalence of vitamin $\mathrm{D}$ deficiency in women, with the highest number of daily cases in countries with higher latitude and in people with increased pigmentation of the skin (5). Vitamin D deficiency has been associated with several metabolic and cardiovascular abnormalities, including hypertension, diabetes mellitus, metabolic syndrome, obesity, vascularinflammation, left ventricular hypertrophy and congestive heart failure (6-8). During menopause, women may be particularly susceptible to the consequences of vitamin $\mathrm{D}$ deficiency since in this period of life oestrogen decreases, resulting in decreased bone mineral density (BMD) and lean mass, increased fat mass, and an increased risk of metabolic syndrome (MS) and cardiovascular morbidities (9-12). According to the International Diabetes Federation (IDF), the diagnosis of MS requires the presence of abdominal obesity associated with two of the following criteria: arterial hypertension, hypertriglyceridemia, reduced HDL-cholesterol, and elevated fasting glycaemia (13). The abdominal obesity associated with MS is a wellestablished cardiovascular risk factor and is frequently associated with hypovitaminosis D (12).

Nevertheless, there have been divergences among the studies on the relationship between serum vitamin D levels and the various components of MS and body composition (14-16). Thus, the objective of this cross-sectional study was to compare the body composition, nutritional factors and metabolic parameters related to MS in menopausal women sufficient, insufficient and deficient in vitamin D.

\section{SUBJECTS AND METHODS}

A cross-sectional descriptive study was carried out with postmenopausal women who were recruited from outpatient clinics of the Endocrine Division (SEMPR) of the Federal University Hospital in Curitiba, South 
of Brazil, between February 2012 and March 2013. Menopause was defined through the 12-month criterion of amenorrhea (absence of menstruation) (17). The exclusion criteria were women in the menacme; those older than 70 years; patients with known diabetes mellitus, renal, hepatic or cardiorespiratory dysfunctions, bone diseases, secondary osteoporosis or neoplasias; and women in use of any medication in the last 6 months that according to medical judgement could interfere with glycaemia and/or bone metabolism.

The study was approved by the Human Research Ethics Committee of our academic institution. All participants were informed about the research procedures and signed the informed consent term.

\section{Clinical evaluation}

The clinical evaluation included the collection of personal data, general clinical status with emphasis on concomitant medications, presence of chronic diseases, blood pressure (BP), waist circumference (WC), weight, height and body mass index (BMI). The number of calories ingested daily through food was calculated using data from the 24-hour food recall and Clinical Diet Win ${ }^{\circledR}$ Software 2002 (15). The measurements were performed according to WHO recommendations (18) using a $150 \mathrm{~kg}$ scale with an accuracy of $1 \mathrm{~kg}$ and a stadiometer with an accuracy of $1 \mathrm{~mm}$. The BP was measured twice by the auscultatory method, with the participants seated, and it was defined as normal when less than $130 / 85 \mathrm{mmHg}$ and abnormal when equal or greater than this cut-off (18). The study group was classified according to their BMI in: normal weight 18.0-24.9 kg/m²; overweight $25.0-29.9 \mathrm{~kg} / \mathrm{m}^{2}$; obese grade $130.0-34.9 \mathrm{~kg} / \mathrm{m}^{2}$, obese grade $235.0-39.9$ $\mathrm{kg} / \mathrm{m}^{2}$ and obese grade $3 \geq 40 \mathrm{~kg} / \mathrm{m}^{2}$ (19). WC was considered normal if less than $80 \mathrm{~cm}$ and altered if equal or greater than $80 \mathrm{~cm}$. A WC between 80 and $87 \mathrm{~cm}$ was considered of an increased risk for cardiovascular events in overweight/obese women and equal or above $88 \mathrm{~cm}$ was considered of very high increased risk $(20,21)$.

\section{Laboratory tests}

Peripheral venous blood samples were collected after 8 hours of fasting and stored at $-80^{\circ} \mathrm{C}$ for analysis. Blood glucose was evaluated by hexoquinase/G-6-PD and values $\geq 100 \mathrm{mg} / \mathrm{dL}$ were considered abnormal; serum insulin levels were determined by chemiluminescence (CL), with values of reference (VR) of 25 to $30 \mathrm{uUI} /$ $\mathrm{mL}$ and intra-assay coefficient of variation $(\mathrm{CV})<$ 10\%. HOMA-IR was calculated with the following formula: glycemia $(\mathrm{mg} / \mathrm{dL}) \mathrm{X}$ insulin $(\mathrm{uUI} / \mathrm{mL}) / 405$. C-reactive protein (CRP) was measured by the turbidometry method, with a limit of detection below $0.5 \mathrm{mg} / \mathrm{dL}$ and $\mathrm{CV}<10 \%$. The colorimetric enzymatic method with a VR $<200 \mathrm{mg} / \mathrm{dL}$ was used for the determination of total cholesterol. HDL-cholesterol was measured by direct/homogeneous method and values $\leq 50 \mathrm{mg} / \mathrm{dL}$ were considered abnormal. LDL-cholesterol was determined by the Friedwald formula and scored at optimal values when $\leq 100$ $\mathrm{mg} / \mathrm{dL}$, desirable at values between 101-129 mg/dL, borderline 130-159 mg/dL and high $\geq 160 \mathrm{mg} / \mathrm{dL}$. Serum triglycerides (TG) was measured by the glycerolphosphate oxidase method and hypertriglyceridemia was defined by levels $\geq 150 \mathrm{mg} / \mathrm{dL}$. Creatinine was evaluated by the picratecalcalino method with a VR of $0.57-1.11 \mathrm{mg} / \mathrm{dL}$. TGO and TGP were evaluated by $\mathrm{NADPH}$, with a VR varying between $0-55 \mathrm{IU} / \mathrm{L}$ and 5-34 IU/L, respectively.

Serum calcium was determined by the Arsenazzo III method with a VR of $8.6-10.3 \mathrm{mg} / \mathrm{dL}$ and serum phosphorus by the UV phosphomolybdate method with a VR of $2.3-4.7 \mathrm{mg} / \mathrm{dL}$. All measurements of PTH and vitamin D $[25(\mathrm{OH}) \mathrm{D}]$ were determined simultaneously in one run by CL, with a VR of 11.7 $61.1 \mathrm{pg} / \mathrm{mL}$ and $\mathrm{CV}<10 \%$ for PTH and VR of 30 $100 \mathrm{ng} / \mathrm{mL}$ and $\mathrm{CV}<10 \%$ for $25(\mathrm{OH}) \mathrm{D}$. According to the $25(\mathrm{OH}) \mathrm{D}$ measurements, the participants were classified as having vitamin $\mathrm{D}$ deficiency when serum levels were $\leq 20 \mathrm{ng} / \mathrm{ml}$, insufficiency when levels were between 20.1 and $29.9 \mathrm{ng} / \mathrm{mL}$ and sufficiency when $\geq 30 \mathrm{ng} / \mathrm{mL}(22)$.

\section{Body composition}

Measurements of lumbar spine ( $\mathrm{Ll}$ to L4) and total femoral BMD, as well as those of body composition (percentage total fat), were performed with a properly calibrated Lunar Prodigy Advance (GE Healthcare, Madison, WI, USA), with a coefficient of variation of $2 \%$ and by the same examiner.

\section{Statistical analysis}

Statistical analyses were performed with the statistical package GraphPad Prism. All data are presented as 
the mean $\pm \mathrm{SD}$, except as otherwise noted. To analyse the normality of the data, the Shapiro-Wilk test was used, which resulted in non-normal data. Thus, nonparametric tests were used to analyse the variables.

For comparative analysis between groups, the Friedman test (with Dunn's a posteriori test) was used for the quantitative variables. In the case of qualitative variables, the chi-square test was used. In the insufficient and deficient groups, the Mann-Whitney test was used for comparisons of the quantitative variables, and the chi-square test and Fisher's exact test were used for the qualitative variables.

For the tests between variables, Pearson's correlations were used, following the theorem of large numbers. From the correlation index, shape and direction can be interpreted according to the concept that directly proportional correlations have a positive sign since inversely proportional correlations have a negative sign (23). In all cases, a level of significance of $5 \%(\mathrm{p}<0.05)$ was considered.

\section{RESULTS}

The study group consisted of 106 postmenopausal women with a mean $( \pm \mathrm{SD})$ age of $56.5 \pm 6.1$ years (range 43-70) and BMI of $28.2 \pm 4.9 \mathrm{~kg} / \mathrm{m}^{2}$ (range 19.7-41.1). In the whole group, serum levels of $25(\mathrm{OH}) \mathrm{D}$ were $21.1 \pm 7.0 \mathrm{ng} / \mathrm{mL}$ (range 7.5-55.0), with 11 women $(10.4 \%)$ classified as sufficient, 50 $(47.2 \%)$ as insufficient and $45(42.4 \%)$ as deficient in vitamin $\mathrm{D}$. The main clinical features of the three study groups are summarized in Table 1. There were no significant differences among the groups.

Table 2 shows the comparisons between anthropometric measurements and body composition parameters evaluated by DXA in the three study groups. Again, no statistically significant differences were identified among vitamin D sufficient, insufficient and deficient postmenopausal women. The results of the laboratory tests (Table 3 ) showed a difference only in the insufficient and deficient groups in relation to serum calcium levels and TGP. Serum calcium was significantly higher in the deficient group $(9.4 \pm 0.5$ vs. $9.2 \pm 0.3 \mathrm{mg} / \mathrm{dL}$ in the insufficient group, $\mathrm{p}=$ 0.04 ), whereas serum TGP was significantly lower in the deficient group $(18.4 \pm 9.6$ vs. $24.0 \pm 16.2 \mathrm{mg} / \mathrm{dL}$ in the insufficient group, $\mathrm{p}=0.047)$.

There were statistically significant inverse correlations between serum $25(\mathrm{OH}) \mathrm{D}$ levels with serum levels of $\mathrm{TG}(\mathrm{r}=0,27 ; \mathrm{p}=0,006)$, total cholesterol $(\mathrm{r}=-0,25$; $\mathrm{p}=0,011)$ and $\operatorname{LDL}(\mathrm{r}=-0,22 ; \mathrm{p}=0,028)$.

The calcium dosage presented a significant difference when the insufficient and deficient vitamin D groups were compared. Thus, a correlation was performed between the three groups with the glycaemia values and the HOMA calculation to verify if the serum calcium

Table 1. Clinical characteristics of postmenopausal women classified as sufficient, insufficient and deficient in vitamin $D$

\begin{tabular}{|c|c|c|c|}
\hline Characteristic & Sufficient $(n=11)$ & Insufficient $(n=50)$ & Deficient $(n=45)^{*}$ \\
\hline Age (yrs) & $54.9 \pm 5.9$ & $56.2 \pm 5.4$ & $57.3 \pm 6.9$ \\
\hline Body mass index (BMl, $\left.\mathrm{kg} / \mathrm{m}^{2}\right)$ & $28.7 \pm 5.4$ & $28.9 \pm 4.9$ & $27.4 \pm 4.7$ \\
\hline \multicolumn{4}{|l|}{ BMI classification (\%) } \\
\hline Normal & 27.3 & 18 & 33.3 \\
\hline Overweight & 36.4 & 46 & 37.8 \\
\hline Obesity grade I & 18.2 & 22 & 20 \\
\hline Obesity grade II & 18.2 & 12 & 8.9 \\
\hline Obesity grade III & 0 & 2 & 0 \\
\hline Waist circumference (cm) & $91.2 \pm 13.0$ & $93.8 \pm 12.4$ & $89.5 \pm 9.2$ \\
\hline \multicolumn{4}{|l|}{ Cardiovascular risk (\%) } \\
\hline Normal $(W C \leq 80 \mathrm{~cm})$ & 27.3 & 10 & 20 \\
\hline High (WC 81-87 cm) & 9.1 & 18.0 & 24.4 \\
\hline Very high $(W C \geq 88 \mathrm{~cm})$ & 63.6 & 72.0 & 55.6 \\
\hline \multicolumn{4}{|l|}{ Blood pressure (\%) } \\
\hline Abnormal & 54.5 & 44 & 35.6 \\
\hline Normal & 45.5 & 56 & 64.4 \\
\hline
\end{tabular}

*All $p$ values were $>0.05$. 
value would be related to the other groups variables involved with insulin resistance and type 2 diabetes.

There were no significant differences between the three groups in relation to the SM criteria for the three groups nor when there was a comparison between the insufficient and vitamin D-deficient groups.

Through analysis of the 24-hour recall, it was possible to verify that the average dietary intake of vitamin $\mathrm{D}$, calcium and cholesterol was lower in the insufficient group (Table 4).

\section{DISCUSSION}

There was a high prevalence of hypovitaminosis D in the studied group, where only $10 \%$ of the 106 women had adequate vitamin $\mathrm{D}$ levels (considering a cut-off point above $30 \mathrm{ng} / \mathrm{mL}$ ) and $90 \%$ were deficient or insufficient. These values are higher than those found in cohort studies of menopausal women, which showed rates of $67 \%$ and $68 \%$ for hypovitaminosis D $(24,25)$. In another study with 93 postmenopausal women living

Table 2. Anthropometric characteristics and body composition parameters by DXA assessment of postmenopausal women classified as sufficient, insufficient and deficient in vitamin D

\begin{tabular}{lccc}
\hline Variable & Sufficient $(\mathbf{n}=\mathbf{1 1})$ & Insufficient $(\mathbf{n}=\mathbf{5 0})$ & Deficient $(\mathbf{n}=\mathbf{4 5})$ \\
\hline Gynoid adipose mass (\%) & $48.3 \pm 5.9$ & $48.5 \pm 5.5$ & $47.2 \pm 6.5$ \\
Android adipose mass (\%) & $47.6 \pm 10.9$ & $48.2 \pm 7.5$ & $46.9 \pm 8.0$ \\
Total adipose, \% & $41.9 \pm 7.4$ & $41.8 \pm 6.0$ & $40.5 \pm 7.0$ \\
Truncal fat (\%) & $43.3 \pm 8.6$ & $43.8 \pm 6.8$ & $42.3 \pm 7.3$ \\
BMD L1-L4 (g/cm²) & $1.01 \pm 0.10$ & $1.07 \pm 0.15$ & $1.06 \pm 0.13$ \\
BMD total femur (g/cm) & $0.90 \pm 0.10$ & $0.96 \pm 0.15$ & $0.92 \pm 0.12$ \\
BMC L1-L4 (g) & $50.8 \pm 7.1$ & $54.2 \pm 10.7$ & $53.6 \pm 9.1$ \\
Bone mineral density (\%) & & & 24.4 \\
Normal & 9.1 & 30.0 & 51.1 \\
Osteopenia & 81.8 & 50.0 & 24.4 \\
Osteoporosis & 9.1 & 20.0 & \\
\hline
\end{tabular}

BMD L1-L4: bone mineral density lumbar spine; BMC: bone mineral content.

${ }^{*}$ All $p$ values were $>0.05$.

Table 3. Characteristics of the biochemical exams of postmenopausal women classified as sufficient, insufficient and deficient in vitamin D

\begin{tabular}{|c|c|c|c|}
\hline Variable & Sufficient $(n=11)$ & Insufficient ( $n=50)$ & Deficient $(n=45)$ \\
\hline Total cholesterol (mg/dL) & $223.5 \pm 37.2(233.0)$ & $209.3 \pm 41.6(208.0)$ & $226.4 \pm 46.5(228.0)$ \\
\hline Triglycerides (mg/dL) & $113.7 \pm 42.7(92.0)$ & $122.6 \pm 56.9(107.0)$ & $135.6 \pm 61.0(124.0)$ \\
\hline $\mathrm{HDL}$ (mg/dL) & $52.1 \pm 10.0(52.0)$ & $45.7 \pm 10.2(44.0)$ & $47.9 \pm 12.5(47.0)$ \\
\hline LDL (mg/dL) & $148.8 \pm 34.2(154.0)$ & $139.8 \pm 38.0(139.5)$ & $151.3 \pm 39.4(152.0)$ \\
\hline Glycemia (mg/dL) & $95.0 \pm 9.6(92.0)$ & $93.9 \pm 12.2(92.0)$ & $90.7 \pm 8.7(89.0)$ \\
\hline Insulin (uUl/mL) & $10.4 \pm 5.3(11.1)$ & $10.9 \pm 6.1(9.4)$ & $10.1 \pm 5.9(7.8)$ \\
\hline HOMA-IR & $2.47 \pm 1.30(2.36)$ & $2.64 \pm 1.78(2.15)$ & $2.33 \pm 1.58(1.85)$ \\
\hline Creatinine (mg/dL) & $0.73 \pm 0.08(0.7)$ & $0.73 \pm 0.12(0.7)$ & $0.71 \pm 0.10(0.7)$ \\
\hline TGO (UI/L) & $20.2 \pm 7.3(18)$ & $20.8 \pm 9.5(18)$ & $19.0 \pm 5.5(18)$ \\
\hline TGP (UI/L) & $20.1 \pm 6.8(20)^{\star *}$ & $24.0 \pm 16.2(19)$ & $18.4 \pm 9.6(16)$ \\
\hline Albumin (mg/dL) & $4.07 \pm 0.20(4.0)$ & $3.96 \pm 0.22(4.0)$ & $3.96 \pm 0.21(4.0)$ \\
\hline Calcium (mg/dL) & $9.35 \pm 0.27(9.4)$ & $9.20 \pm 0.34(9.2)$ & $9.38 \pm 0.50(9.3)^{\star}$ \\
\hline Phosphorus (mg/dL) & $3.51 \pm 0.45(3.6)$ & $3.43 \pm 0.46(3.3)$ & $3.31 \pm 0.62(3.4)$ \\
\hline PTH (pg/mL) & $50.2 \pm 11.5(50.1)$ & $56.3 \pm 22.4(50.8)$ & $59.3 \pm 17.7$ (3.6) \\
\hline $\mathrm{ng} / \mathrm{mL}$ (mg/dL) & $0.38 \pm 0.10(0.33)$ & $0.45 \pm 0.25(0.33)$ & $0.62 \pm 1.05(0.33)$ \\
\hline
\end{tabular}

HDL: high density lipoprotein; LDL: low density lipoprotein; HOMA-IR: homeostatic model assessment for insulin resistance; TGO: glutamic-oxalacetic transaminase; TPG: pyruvic glutamic transaminase; PCR-C: reactive protein; mg/dL: milligrams per decilitre; UUI/mL: international micro unit per millilitre; UI/L: intentional unit per litre; pg/mL: picogram per millilitre. Values are means \pm standard deviations, with medians in parentheses or percentage frequencies. ${ }^{*} p=0.04$ vs. insufficient. ${ }^{\star \star} p=0.04$ vs. insufficient. 
in the city of Recife, the authors found a prevalence of $24 \%$ of vitamin D deficiency, which was lower than this study; this study also found a mean serum vitamin D concentration of $28.8 \mathrm{ng} / \mathrm{mL}$, higher than the $21.1 \mathrm{ng} / \mathrm{mL}$ observed in our patients (with cut-off point for deficiency less than $20 \mathrm{ng} / \mathrm{mL}$ ), because according to with the authors themselves the incidence of solar radiation is higher because Reef is closer to the equator (26).

The current study found an inverse correlation between serum vitamin D levels and serum levels of TG, total cholesterol and LDL-cholesterol, indicating a trend towards an unfavourable lipid profile in menopausal women with lower levels of vitamin D. However, we did not find significant differences when we analysed and compared the groups deficient and insufficient in relation to body composition and metabolic variables. Similarly, these groups did not differ when analysed according to the SM criteria presented (27).

A study conducted by Iranian researchers has shown that the serum vitamin $\mathrm{D}$ concentration was lower in subjects with MS, similar to this study, compared to individuals without MS (27). To identify the relationship between daily intake of vitamin $\mathrm{D}$, serum $25(\mathrm{OH}) \mathrm{D}$ levels and prevalence of MS, these researchers compared the plasma and nutritional variables of 128 healthy individuals and 122 individuals with a diagnosis of MS (27). The results showed that $98.4 \%$ of the patients in the MS group and $88.3 \%$ of the healthy individuals presented vitamin $\mathrm{D}$ deficiency $[25(\mathrm{OH}) \mathrm{D}<20 \mathrm{ng} / \mathrm{mL}]$. This difference was statistically significant $(\mathrm{p}=0.005)$. Furthermore, concentrations of $25(\mathrm{OH}) \mathrm{D}$ were significantly associated with waist circumference $(\mathrm{p}=0.001)$, HDL $(\mathrm{p}=0.001)$ and triglyceride levels $(\mathrm{p}=0.012)$. The authors concluded that there is an association between vitamin D and MS. This study, however, failed to confirm the relationship between vitamin D deficiency and a higher prevalence of MS.
A study evaluating micronutrient concentrations in women $(\mathrm{n}=8,137)$ who participated in the National Health and Nutrition Examination Survey III (NHANES III) showed that in postmenopausal women there was a negative association of vitamin $\mathrm{D}$ with BMI $(25,28)$. Other researchers have observed that the percentage of body fat was also strongly associated with a low vitamin $\mathrm{D}$ concentration (23). The present study did not demonstrate a negative association with BMI and fat percentage.

Vitamin D deficiency has been associated with the development of cardiovascular diseases, hypertension, neoplasias, and diabetes, suggesting a crucial role for this vitamin in several homeostasis systems (29). Screening for vitamin D deficiency is cost-effective in some specific populations - postmenopausal, elderly, institutionalized, and pregnant women. In this study, vitamin D levels were not related to blood pressure and glycaemic indexes.

We observed differences between serum levels of $\mathrm{Ca}$ and TGP among the women who were insufficient and deficient in vitamin $\mathrm{D}$; there were higher values of $\mathrm{Ca}$ and lower values of TGP. Ca intake was also significantly higher in the deficient group compared to the insufficient group, as was as the ingestion of cholesterol-containing foods and total daily caloric intake. It is known that adequate plasma concentrations of $25(\mathrm{OH}) \mathrm{D}$ are required to allow adequate absorption of calcium administered orally. A recent study showed that calcium absorption was $65 \%$ higher when plasma concentrations of $25(\mathrm{OH}) \mathrm{D}$ were in the mean of 34,8 $\mathrm{ng} / \mathrm{mL}(30)$.

Although diet represents only $10 \%$ to $20 \%$ of the vitamin $\mathrm{D}$ necessary for the proper functioning of the organism, the dietary sources of vitamin $\mathrm{D}$ are scarce, and individuals depend mainly on the skin for production vitamin $\mathrm{D}$, catalysed by solar UVB rays (31).

Vitamin D is found in food sources such as cod liver oil and fatty fish (salmon, tuna, and mackerel) or

Table 4. Dietary ingestion in postmenopausal women classified as sufficient, insufficient and deficient in vitamin D

\begin{tabular}{lcccc}
\hline 24-hour recall & Sufficient $(\mathbf{n}=\mathbf{1 1})$ & Insufficient $(\mathbf{n}=\mathbf{5 0})$ & Deficient $(\mathbf{n}=\mathbf{4 5})$ & P value \\
\hline Vitamin D, $\mu \mathrm{g}$ & $3.93 \pm 0.80(3.79)$ & $0.84 \pm 1.12(0.43)$ & $1.32 \pm 0.90(1.27)^{\star *}$ & $<0.001^{\star}$ \\
Calcium, $\mathrm{mg}$ & $395.0 \pm 199.2(379.3)$ & $238.7 \pm 174.1(199.6)$ & $248.6 \pm 130.5(234.3)$ & $0.021^{*}$ \\
Kcal/total, kcal & $1649 \pm 601.4(1647)$ & $1406 \pm 608.1(1257)$ & $1985 \pm 637.8(2123)^{\star \star *}$ & $<0.001^{*}$ \\
Cholesterol, $\mathrm{mg}$ & $314.2 \pm 601.4(207.5)$ & $126.3 \pm 94.3(109.5)$ & $199.9 \pm 135.1(168.1)^{* \star \star *}$ & $<0.001^{*}$ \\
Fibre $(\mathrm{g})$ & $8.6 \pm 3.2(8.0)$ & $9.1 \pm 5.5(8.5)$ & $7.7 \pm 2.6(7.7)$ & 0.633 \\
\hline
\end{tabular}

${ }^{*} p<0.05 .{ }^{* \star} p=0.026$ vs. insufficient. ${ }^{* \star *} p=<0.001$ vs. insufficient. ${ }^{\star \star \star \star} p=0.003$ vs. insufficient. 
through endogenous cutaneous synthesis, which is the main source of this vitamin for most humans (31).

Vitamin D intake was higher in women whose levels were insufficient. Recent studies in the literature have correlated vitamin D supplementation with lower mortality rates; according to these data, we can suggest supplementation for correction of hypovitaminosis $\mathrm{D}$ and dietary inadequacy aimed at postmenopausal women $(32,33)$.

In conclusion, in this group of menopausal women, there were no significant differences in body composition and metabolic parameters between women with insufficient and deficient levels of vitamin $\mathrm{D}$. Further, lower vitamin D levels were associated with an unfavourable lipid profile; there was a high prevalence of hypovitaminosis D, corresponding to $90 \%$ of the sample; and serum vitamin D levels were influenced by dietary intake of vitamin $\mathrm{D}$.

Funding statement: no funding statement to make.

Disclosure: no potential conflict of interest relevant to this article was reported.

\section{REFERENCES}

1. Palacios C, Gonzalez L. Is vitamin D deficiency a major global public health problem? J Steroid Biochem Mol Biol. 2014;144: 138-45.

2. Santos AEPD, Queiroz DJM, Neves JPR, Lacerda LM, Gonçalves $M$, Carvalho AT. Prevalence of hypovitaminosis D and associated factors in adolescent students of a capital of northeastern Brazil. Nutr Hosp. 2017;34(5):1416-23.

3. Silva BCC, Camargos BM, Fujii JB, Dias EP, Soares MMS. Prevalência de deficiência e insuficiência de vitamina $D$ e sua correlação com PTH, marcadores de remodelação óssea e densidade mineral óssea, em pacientes ambulatoriais. Arq Bras Endocrinol Metabol. 2008;52(3):482-8.

4. Autier P, Boniol M, Pizot C, Mullie P.Vitamin D status and ill health: a systematic review. Lancet Diabetes Endocrinol. 2014;2(1):76-89.

5. Holick M. Vitamina D como um tratamento tão simples pode reverter doenças tão importantes. São Paulo: Editora Fundamento; 2012.

6. Nakashima A, Yokoyama K, Yokoo T, Urashima M. Role of vitamin $\mathrm{D}$ in diabetes mellitus and chronic kidney disease. World $\mathrm{J}$ Diabetes. 2016;7(5):89-100.

7. Anderson JL, May HT, Horne BD, BairTL, Hall NL, Carlquist JF, et al. Relation of vitamin D deficiency to cardiovascular risk factors, disease status, and incident events in a general healthcare population. Am J Cardiol. 2010;106(7):963-8.

8. Mihos CG, Cruz JADL, Hernandez A, Santana O. Vitamin D deficiency and supplementation in cardiovascular disorders. Cardiol Rev. 2017;25(4):189-96.

9. Lerchbaum E. Vitamin D and menopause - a narrative review. Maturitas. 2014;79(1):3-7.

10. Kaur J. A comprehensive review on metabolic syndrome. Cardiol Res Pract. 2014;2014:943162.
11. Vitezova A, Zillikens MC, van Herpt TT, Sijbrands EJ, Hofman A, Uitterlinden AG, et al. Vitamin $D$ status and metabolic syndrome in the elderly: the Rotterdam study. Eur J Endocrinol. 2015; 172(3):327-35.

12. O'Neill S, O'Driscoll L. Metabolic syndrome: a closer look at the growing epidemic and its associated pathologies. Obes Rev. 2015;16(1):1-12.

13. Simmons RK, Alberti KG, Gale EA, Colagiuri S, Tuomilehto $J$, Qiao Q, et al. The metabolic syndrome: useful concept or clinical tool? Report of a WHO expert consultation. Diabetologia. 2010;53(4):600-5.

14. Chacko SA, Song Y, Manson JE, van Horn L, Eaton C, Martin LW, et al. Serum 25-hydroxyvitamin $D$ concentrations in relation to cardiometabolic risk factors and metabolic syndrome in postmenopausal women. Am J Clin Nutr. 2011;94(1):209-17.

15. Henn RL, Fuchs SC, Moreira LB, Fuchs FD. Development and validation of a food frequency questionnaire (FFO-Porto Alegre) for adolescent, adult and elderly populations from Southern Brazil. Cad Saude Publica. 2010;26(11):2068-79.

16. Strange RC, Shipman KE, Ramachandran S. Metabolic syndrome: a review of the role of vitamin $D$ in mediating susceptibility and outcome. World J Diabetes. 2015;6(7):896-911.

17. Butler L, Santoro N. The reproductive endocrinology of the menopausal transition. Steroids. 2011;76(7):627-35.

18. de Onis M, Onyango A, Borghi E, Siyam A, Blossner M, Lutter C. Worldwide implementation of the WHO child growth standards. Public Health Nutr. 2012;15(9):1603-10.

19. World Health Organization. Waist circumference and waist-hip ratio report of a WHO expert consultation. Geneva: World Health Organization; 2008.

20. Lee DC, Sui X, ChurchTS, Lavie CJ, Jackson AS, Blair SN. Changes in fitness and fatness on the development of cardiovascular disease risk factors hypertension, metabolic syndrome, and hypercholesterolemia. J Am Coll Cardiol. 2012;59(7):665-72.

21. Hamer M, Stamatakis E. Metabolically healthy obesity and risk of all-cause and cardiovascular disease mortality. J Clin Endocrinol Metab. 2012;97(7):2482-8.

22. Holick MF, Binkley NC, Bischoff-Ferrari HA, Gordon CM, Hanley DA, Heaney RP, et al. Evaluation, treatment, and prevention of vitamin D deficiency: an endocrine society clinical practice guideline. J Am Coll Cardiol. 2011;96(7):1911-30.

23. Zar J. Biostatistical analysis. Harlow: Pearson; 2009.

24. Arantes HP, Kulak CA, Fernandes $C E$, Zerbini $C$, Bandeira $F$, Barbosa IC, et al. Correlation between 25-hydroxyvitamin D levels and latitude in Brazilian postmenopausal women: from the Arzoxifene generations trial. Osteoporos Int. 2013;24(10):2707-12.

25. Russo LA, Gregorio LH, Lacativa PG, Marinheiro LP. Concentration of 25-hydroxyvitamin $D$ in postmenopausal women with low bone mineral density. Arq Bras Endocrinol Metab. 2009;53(9):1079-87.

26. Bandeira F, Griz L, Freese E, Lima DC, Thé AC, Diniz ET, et al. Vitamin $D$ deficiency and its relationship with bone mineral density among postmenopausal women living in the tropics. Arq Bras Endocrinol Metab. 2010;54(2):227-32.

27. Ghanei L, Ziaee A, Rostami P, Oveisi S, Esmailzadehha N, Kazemifar AM, et al. Association of serum 25-hydroxyvitamin d levels and vitamin $D$ dietary intake with metabolic syndrome: a case control study. J Res Health Sci. 2015;15(1):32-6.

28. Snijder MB, van Dam RM, Visser M, Deeg DJ, Dekker JM, Bouter LM, et al. Adiposity in relation to vitamin $D$ status and parathyroid hormone levels: a population-based study in older men and women. J Clin Endocrinol Metab. 2005;90(7):4119-23.

29. Alves M, Bastos M, Leitão F, Marques G, Ribeiro G, Carrilho F. Vitamin D - importance of laboratory evaluation. Rev Port Endocrinol Diabetes Metab. 2013;8(1):32-9.

30. Bischoff-Ferrari HA, WillettWC, Orav EJ, Lips P, Meunier PJ, Lyons $R A$, et al. A pooled analysis of vitamin $D$ dose requirements for fracture prevention. N Engl J Med. 2012;367(1):40-9. 
31. Maeda SS, Borba VZ, Camargo MB, Silva DM, Borges JL, Bandeira $F$, et al. Recommendations of the Brazilian society of endocrinology and metabology (SBEM) for the diagnosis and treatment of hypovitaminosis D. Arq Bras Endocrinol Metab. 2014;58(5):411-33.

32. Rejnmark L, Avenell A, Masud T, Anderson F, Meyer HE, Sanders $\mathrm{KM}$, et al. Vitamin $D$ with calcium reduces mortality: patient level pooled analysis of 70,528 patients from eight major vitamin $D$ trials. J Clin Endocrinol Metab. 2012;97(8):2670-81.
33. Rizzoli R, Boonen S, Brandi ML, Bruyere O, Cooper C, Kanis JA, et al. Vitamin D supplementation in elderly or postmenopausal women: a 2013 update of the 2008 recommendations from the European society for clinical and economic aspects of Osteoporosis and Osteoarthritis (ESCEO). Curr Med Res Opin. 2013;29(4):305-13. 